\title{
Role of Magnetic Field on Natural Convective Towards a Semi- Infinite Vertically Inclined Plate in Presence of Hall Current with Numerical Solutions: A Finite Difference Technique
}

\author{
Bandham Saidulu \\ Assistant Professor, Princeton Degree \& PG College, Ramanthapur, Hyderabad, Telangana State, India. \\ *Corresponding Author: Bandham Saidulu, Assistant Professor, Princeton Degree \& PG College, \\ Ramanthapur, Hyderabad, Telangana State, India.
}

\begin{abstract}
In the present research work, the simultaneous effects of magnetic field and Hall current on an unsteady natural convective flow of incompressible, electrically conducting fluid towards a semi-infinite vertically inclined plate in presence of heat and mass transfer studied. For the numerical results, the basic governing non-linear partial differential equations converted into linear coupled partial differential equations using non-dimensional quintiles and are solved, numerically by finite difference method for velocity (both primary and secondary), temperature, concentration fields are discussed through graphs with the help of engineering parameters such as Grashof number for heat transfer, Grashof number for mass transfer, Prandtl Number, Schmidt Number, Hartmann number and Hall parameter.
\end{abstract}

Keywords: Natural Convection; MHD; Hall current; Finite difference method;

\section{Nomenclature:}

List of Variables:

$T^{\prime} \quad$ Temperature of the fluid , $K$

$C^{\prime} \quad$ Concentration of the fluid, $\mathrm{Kg} / \mathrm{m}^{3}$

$C_{w}^{\prime} \quad$ Concentration near the plate, $\mathrm{Kg} / \mathrm{m}^{3}$

$C_{\infty}^{\prime} \quad$ Concentration in the fluid far away from the plate, $\mathrm{Kg} / \mathrm{m}^{3}$

$T_{w}^{\prime} \quad$ Temperature of the plate, $K$

$u^{\prime} \quad$ Velocity component in $x^{\prime}$-direction, $\mathrm{m} / \mathrm{s}$

$w^{\prime} \quad$ Velocity component in $z^{\prime}-$ direction, $m / s$

$y^{\prime} \quad$ Spatial co-ordinate normal to the plate, $m$

$x^{\prime} \quad$ Spatial co-ordinate along the plate, $m$

$T_{\infty}^{\prime} \quad$ Temperature of the fluid far away from the plate, $K$

$\bar{V} \quad$ Velocity vector, $m / s$

$k \quad$ Thermal conductivity, $W / m K$

$C_{p} \quad$ Specific heat at constant Pressure, $J / k g-K$

$k_{e} \quad$ Mean absorption coefficient

$D \quad$ Chemical molecular diffusivity, $\mathrm{m}^{2} / \mathrm{s}$

$m$ Hall parameter
$U_{o} \quad$ Reference velocity, $\mathrm{m} / \mathrm{s}$

$n_{e} \quad$ Number density of the electron, $\mathrm{kg} / \mathrm{m}^{3}$

$M \quad$ Hartmann number

$P_{e} \quad$ Electron Pressure, $N / m^{2}$

$e \quad$ Electron charge, coulombs

Sc Schmidt Number

Pr Prandtl number

Gc Grashof number for mass transfer

$\mathrm{Gr} \quad$ Grashof number for heat transfer

$g \quad$ Acceleration due to Gravity, $9.81 \mathrm{~m} / \mathrm{s}^{2}$

\section{Greek Symbols:}

$\beta \quad$ Volumetric co-efficient of thermal Expansion, $K^{-1}$

$\mu \quad$ Viscosity, $N s / m^{2}$

$\alpha \quad$ Angle of inclination

$\varepsilon \quad$ Porosity of the porous medium

$\mu_{e} \quad$ Magnetic permeability, Henry/meter

$v \quad$ Kinematics viscosity, $\mathrm{m}^{2} / \mathrm{s}$

$\omega_{e} \quad$ Electron frequency, radian/sec 
Role of Magnetic Field on Natural Convective Towards a Semi-Infinite Vertically Inclined Plate in Presence of Hall Current with Numerical Solutions: A Finite Difference Technique

\begin{tabular}{clll}
$\tau_{e}$ & Electron collision time, $\operatorname{Sec}$ & $\beta^{*}$ Co-efficient of volume expansion with \\
$\sigma$ & Electrical conductivity, $m \mathrm{ho} / \mathrm{m}$ & Species concentration, $\mathrm{m}^{3} / \mathrm{Kg}$ \\
& & Superscripts: \\
$\theta$ & Dimensionless Temperature $(\mathrm{K})$ & \multicolumn{2}{c}{ Subscripts: } \\
$\phi$ & Dimensionless concentration $\left(\mathrm{Kg} / \mathrm{m}^{3}\right)$ & $w$ & Wall condition \\
$\rho$ & Density, $\mathrm{kg} / \mathrm{m}^{3}$ & $p$ & Plate \\
& & $\infty$ & Free stream condition
\end{tabular}

\section{INTRODUCTION}

The studies of free convective flow of viscous incompressible fluid past vertical bodies have wide range of extensive engineering and technological applications. When free convection flows occurs at high temperature, the effects of radiation are found to be posing vital important applications. Thermal radiation is key to many fundamental phenomena surrounding atmosphere, from solar radiation to fire and radiant lamp, which had played a major role in combustion and furnace design, design of fins, nuclear power plants, cooling of towers, gas turbines and various propulsion devices for aircraft, energy utilization, temperature measurements, remote sensing for astronomy, and space exploration. Magneto hydrodynamic flow of heat and mass transfer processes occur in many of the industrial applications: such as cooling of geothermal systems, aerodynamic processes, chemical catalytic reactors and processes, electromagnetic pumps, and Magneto Hydrodynamic power generators etc. Many studies have been carried out to investigate the magneto hydrodynamic past free convective fluid flow. The study of magnetohydrodynamic flow through porous media has been the subject of considerable improvement in the last few decades. In nuclear engineering, the magneto hydrodynamic flow in a porous medium is required for the design of a layer of liquid metal around a thermonuclear fusion-fission hybrid reactor. In metallurgy, a permanent magnetic field can be applied during the solidification process to modify the intensity of the interdendritic flow of the metallic liquid in a porous medium. Dharmendar Reddy et al. ([1] and [2]) studied hall current effect on an unsteady MHD free convection flow past a vertical porous plate with chemical reaction, heat and mass transfer. Srinivasa Rao [3] studied finite element analysis of radiation and mass transfer flow past semi-infinite moving vertical plate with viscous dissipation. Sheri et al. ([4]-[7]) discussed transient approach to heat absorption and radiative heat transfer past an impulsively moving plate with ramped temperature. Venkataramana et al. [8] studied thermal radiation and rotation effect on an unsteady MHD mixed convection flow through a porous medium with Hall current and Heat absorption. Sailaja et al. ([9][12]) discussed finite element solutions of non-newtonian dissipative Casson fluid flow past a vertically inclined surface surrounded by porous medium including constant heat flux, thermal diffusion and diffusion thermo. Sivaiah and Srinivasa Raju and their co-authors ([13]-[14]) studied finite element solution of heat and mass transfer flow with hall current, heat source and viscous dissipation. Ramya et al. ([15]-[18]) discussed boundary layer viscous flow of nanofluids and heat transfer over a nonlinearly isothermal stretching sheet in the presence of heat generation/absorption and slip boundary conditions. Srinivasa Raju ([19] and [20]) studied unsteady MHD boundary layer flow of casson fluid over an inclined surface embedded in a porous medium with thermal radiation and chemical reaction. Srinivasa Raju et al. ([21] and [22]) studied radiation effect on unsteady MHD free convection with Hall current near on an infinite vertical porous plate. Srinivasa Raju [23] studied numerical treatment of casson fluid free convection flow past an infinite vertical plate filled in magnetic field in presence of angle of inclination and thermal radiation using finite element technique. Srinivasa Raju et al. ([24]-[39]) discussed influence of transpiration on unsteady heat transfer MHD fluid flow over an infinite vertical plate in presence of hall current. Srinivasa Raju [40] studied effects of soret and Dufour on natural convective fluid flow past a vertical plate embedded in porous medium in the presence of thermal radiation via finite element method. Srinivasa Raju et al. [41] discussed magnetohydrodynamic chemically reacting flow past vertically inclined permeable plate filled in porous medium with convergence analysis of FEM. Combined influence of thermal diffusion and diffusion thermo on unsteady hydromagnetic free convective fluid flow past an infinite vertical porous plate in presence of chemical reaction studied by Srinivasa Raju [42]. Srinivasa Raju et al. ([43]-[46]) discussed the application of finite element method to unsteady MHD free convection flow past a vertically inclined porous plate including thermal diffusion and diffusion thermo effects. Application of finite element method to MHD mixed convection chemically reacting flow past a vertical porous 
Role of Magnetic Field on Natural Convective Towards a Semi-Infinite Vertically Inclined Plate in Presence of Hall Current with Numerical Solutions: A Finite Difference Technique

plate with cross diffusion and Biot number effects studied by Srinivasa Raju [47]. Simultaneous effects of soret and Dufour on unsteady hydromagnetic free convective chemically reacting fluid flow past an infinite vertical plate filled in porous medium studied by Srinivasa Raju and Sarada [48]. Study of grid independence of finite element method on MHD free convective casson fluid flow with slip effect studied by Srinivasa Raju and Ramesh [49]. Manideep et al. ([50] and [51]) discussed MHD free convection heat transfer Couette flow in rotating system. Maddilety and Srinivasa Raju [52] studied hall effect on an unsteady MHD free convective Couette flow between two permeable plates. Heat and mass transfer effects on MHD natural convective flow past an infinite vertical porous plate with thermal radiation and hall current studied by Ramana Murthy et al. [53]. Sudhakar et al. ([54]-[56]) studied hall effect on an unsteady MHD flow past along a porous flat plate with thermal diffusion, diffusion thermo and chemical reaction. Unsteady MHD free convection flow near on an infinite vertical plate embedded in a porous medium with chemical reaction, hall current and thermal radiation studied by Sarada et al. [57]. Anand Rao et al. ([58]-[67]) studied finite element analysis of unsteady MHD free convection flow past an infinite vertical plate with Soret, Dufour, thermal radiation and heat source. Anand Rao and Srinivasa Raju ([68]-[70]) studied hall effect on an unsteady MHD flow and heat transfer along a porous flat plate with mass transfer and viscous dissipation. Jitthender Reddy et al. ([71]-[79]) discussed chemical reaction and radiation effects on MHD free convection from an impulsively started infinite vertical plate with viscous dissipation. Aruna et al. [80] studied combined influence of Soret and Dufour effects on unsteady hydromagnetic mixed convective flow in an accelerated vertical wavy plate through a porous medium, Krishna Prasad et al. ([81]-[83]) discussed thermal radiation influence on MHD Flow of a rotating fluid with heat transfer through finite element and element free Galerkin solutions.

Motivated by the above reference work, the aim of this investigation is to study the influence of hall current on an unsteady magneto hydrodynamic flow and mass transfer of an electrically conducting incompressible fluid along an infinite vertically inclined plate. Also, the effects of different flow parameters encountered in the equations are studied. The problem is governed by system of coupled non-linear partial differential equations whose exact solution is difficult to obtain. Hence, the problem is solved by using finite difference method, which is more economical from computational view point.

\section{MATHEMATiCAl Formulation}

An unsteady natural convection flow of an electrically conducting viscous incompressible fluid with mass transfer along a porous flat plate has been considered with hall current. In Cartesian coordinate system, let $x^{\prime}$-axis is taken to be along the plate and the $y^{\prime}$-axis normal to the plate. Since the plate is considered infinite in $x^{\prime}$-direction, hence all physical quantities will be independent of $x^{\prime}-$ direction. Let the components of velocity along $x^{\prime}$ and $y^{\prime}$ axes be $u^{\prime}$ and $v^{\prime}$ which are chosen in the upward direction along the plate and normal to the plate respectively. A uniform magnetic field of magnitude $B_{o}$ is applied normal to the plate. The transverse applied magnetic field and magnetic Reynold's number are assumed to be very small, so that the induced magnetic field is negligible. The polarization effects are assumed to be negligible and hence the electric field is also negligible. Initially, for time $t^{\prime} \leq 0$, the plate and the fluid are maintained at the same constant temperature $\left(T_{\infty}^{\prime}\right)$ in a stationary condition with the same species concentration $\left(C_{\infty}^{\prime}\right)$ at all points so that, the Soret and Dufour effects are neglected. When $t^{\prime}>0$, The wall is maintained at constant temperature $\left(T_{w}^{\prime}\right)$ and concentration $\left(C_{w}^{\prime}\right)$ higher than the ambient temperature $\left(T_{\infty}^{\prime}\right)$ and concentration $\left(C_{\infty}^{\prime}\right)$ respectively. The homogeneous chemical reaction of first order with rate constant between the diffusing species and the fluid is assumed. Using the relation $\nabla . \bar{H}=0$ for the magnetic field $\bar{H}=\left(H_{x}, H_{y}, H_{z}\right)$, we obtain $H_{y}=$ constant $=H_{o}$ (say) where $H_{o}$ is the externally applied transverse magnetic field so that $\bar{H}=\left(0, H_{o}, 0\right)$. The equation of conservation of electric charge $\nabla \cdot \bar{J}=0$ gives $j_{y}=$ constant, where $\bar{J}=\left(j_{x}, j_{y}, j_{z}\right)$. We further assume that the plate is non-conducting. This implies $j_{y}=0$ at the plate and hence zero everywhere. When the strength of magnetic field is very large, the generalized Ohm's law in the absence of electric field takes the following form: 
Role of Magnetic Field on Natural Convective Towards a Semi-Infinite Vertically Inclined Plate in Presence of Hall Current with Numerical Solutions: A Finite Difference Technique

$\bar{J}+\frac{\omega_{e} \tau_{e}}{B_{o}} \bar{J} \times \bar{H}=\sigma\left(\mu_{e} \bar{V} \times \bar{H}+\frac{1}{e n_{e}} \nabla P_{e}\right)$

Under the assumption that the electron pressure (for weakly ionized gas), the thermo-electric pressure and ion-slip conditions are negligible, equation (1) becomes:

$j_{x}=\frac{\sigma \mu_{e} H_{o}}{1+m^{2}}\left(m u^{\prime}-w^{\prime}\right)$ and $j_{z}=\frac{\sigma \mu_{e} H_{o}}{1+m^{2}}\left(m w^{\prime}+u^{\prime}\right)$

Where $u^{\prime}$ is the $x^{\prime}$-component of $\bar{V}, w^{\prime}$ is the $z^{\prime}$-component of $\bar{V}$ and $m\left(=\omega_{e} \tau_{e}\right)$ is the hall parameter. Within the above framework, the equations which govern the flow under the usual Boussinesq's approximation are as follows:

$$
\begin{aligned}
& \frac{\partial v^{\prime}}{\partial y^{\prime}}=0 \\
& \frac{\partial u^{\prime}}{\partial t^{\prime}}+v^{\prime} \frac{\partial u^{\prime}}{\partial y^{\prime}}=v \frac{\partial^{2} u^{\prime}}{\partial y^{\prime 2}}-\frac{\sigma \mu_{e}^{2} H_{o}^{2}}{\rho\left(1+m^{2}\right)}\left(u^{\prime}+m w^{\prime}\right)+g \beta\left(T^{\prime}-T_{\infty}^{\prime}\right)(\cos \alpha)+g \beta^{*}\left(C^{\prime}-C_{\infty}^{\prime}\right)(\cos \alpha) \\
& \frac{\partial w^{\prime}}{\partial t^{\prime}}+v^{\prime} \frac{\partial w^{\prime}}{\partial y^{\prime}}=v \frac{\partial^{2} w^{\prime}}{\partial y^{\prime 2}}-\frac{\sigma \mu_{e}^{2} H_{o}^{2}}{\rho\left(1+m^{2}\right)}\left(w^{\prime}-m u^{\prime}\right) \\
& \frac{\partial T^{\prime}}{\partial t^{\prime}}+v^{\prime} \frac{\partial T^{\prime}}{\partial y^{\prime}}=\frac{k}{\rho C_{p}} \frac{\partial^{2} T^{\prime}}{\partial y^{\prime 2}} \\
& \frac{\partial C^{\prime}}{\partial t^{\prime}}+v^{\prime} \frac{\partial C^{\prime}}{\partial y^{\prime}}=D \frac{\partial^{2} C^{\prime}}{\partial y^{\prime 2}}
\end{aligned}
$$

The corresponding initial and boundary conditions are:

$$
\begin{aligned}
& t^{\prime} \leq 0: \quad u^{\prime}=0, \quad w^{\prime}=0, \quad T^{\prime}=T_{\infty}^{\prime}, C^{\prime}=C_{\infty}^{\prime} \quad \text { for all } \quad y^{\prime}
\end{aligned}
$$

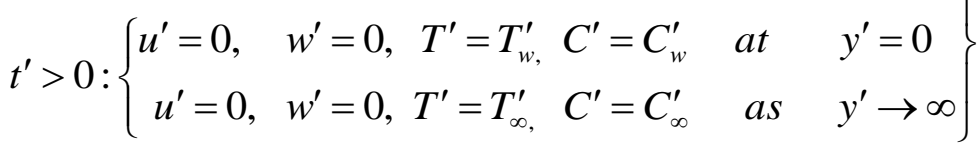

The non-dimensional quantities introduced in the equations (3)-(7) are:

$$
\begin{aligned}
& t=\frac{t^{\prime} U_{o}^{2}}{v}, \quad y=\frac{y^{\prime} U_{o}^{2}}{v},(u, v, w)=\frac{\left(u^{\prime}, v^{\prime}, w^{\prime}\right)}{U_{o}}, \theta=\frac{\left(T^{\prime}-T_{\infty}^{\prime}\right)}{\left(T_{w}^{\prime}-T_{\infty}^{\prime}\right)}, \varphi=\frac{\left(C^{\prime}-C_{\infty}^{\prime}\right)}{\left(C_{w}^{\prime}-C_{\infty}^{\prime}\right)}, M=\frac{\sigma \mu_{e}^{2} H_{0}^{2} v}{\rho U_{o}^{2}}, S c=\frac{v}{D}, G r=\frac{v g \beta\left(T_{w}^{\prime}-T_{\infty}^{\prime}\right)}{U_{o}^{3}}, \\
& G c=\frac{v g \beta^{\prime \prime}\left(C_{w}^{\prime}-C_{\infty}^{\prime}\right)}{U_{o}^{3}}, \operatorname{Pr}=\frac{\mu C_{p}}{k},
\end{aligned}
$$

The governing equations can be obtained in the dimensionless form as:

$$
\begin{aligned}
& \frac{\partial v}{\partial y}=0 \\
& \frac{\partial u}{\partial t}+v \frac{\partial u}{\partial y}=\frac{\partial^{2} u}{\partial y^{2}}-\frac{M}{\left(1+m^{2}\right)}(u+m w)+(G r) \theta(\cos \alpha)+(G c) \phi(\cos \alpha) \\
& \frac{\partial w}{\partial t}+v \frac{\partial w}{\partial y}=\frac{\partial^{2} w}{\partial y^{2}}-\frac{M}{\left(1+m^{2}\right)}(w-m u) \\
& \frac{\partial \theta}{\partial t}+v \frac{\partial \theta}{\partial y}=\frac{1}{\operatorname{Pr}} \frac{\partial^{2} \theta}{\partial y^{2}}
\end{aligned}
$$


Role of Magnetic Field on Natural Convective Towards a Semi-Infinite Vertically Inclined Plate in Presence of Hall Current with Numerical Solutions: A Finite Difference Technique

$$
\frac{\partial \phi}{\partial t}+v \frac{\partial \phi}{\partial y}=\frac{1}{S c} \frac{\partial^{2} \phi}{\partial y^{2}}
$$

The initial and boundary conditions (8) in the non-dimensional form are:

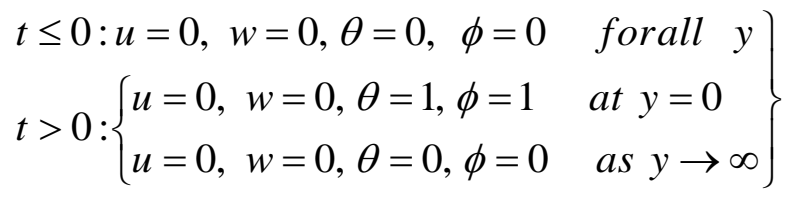

\section{RESULTS AND DISCUSSIONS}

Hall effect study on an unsteady magnetohydrodynamic flow and mass transfer of an electrically conducting incompressible newtonian fluid along an infinite vertically inclined plate with heat and mass transfer has been studied and solved by using finite difference method. The effects of material parameters such as Grashof number for heat transfer, Grashof number for mass transfer, Prandtl number, Schmidt number, Hartmann number and Hall parameter separately in order to clearly observe their respective effects on the primary velocity, secondary velocity, temperature and concentration profiles of the flow. During the course of numerical calculations of the primary velocity, secondary velocity, temperature and concentration the values of the Prandtl number are chosen for Mercury ( $\mathrm{Pr}$ $=0.025)$, Air at $25^{\circ} \mathrm{C}$ and one atmospheric pressure $(\operatorname{Pr}=0.71)$, Water $(\operatorname{Pr}=7.00)$ and Methanol $(\operatorname{Pr}$ $=11.62$ ). To focus out attention on numerical values of the results obtained in the study, the values of $S c$ are chosen for the gases representing diffusing chemical species of most common interest in air namely Hydrogen $(S c=0.22)$, Helium $(S c=0.30)$, Water-vapour $(S c=0.60)$, Oxygen $(S c=0.66)$ and Ammonia $(S c=0.78)$. For the physical significance, the numerical discussions in the problem and at $t=1.0$, stable values for primary velocity, secondary velocity, temperature and concentration fields are obtained. To examine the effect of parameters related to the problem on the velocity field and skin-friction numerical computations are carried out at $\operatorname{Pr}=0.71$. To find out the solution of this problem, we have placed an infinite vertical plate in a finite length in the flow. Hence, we solve the entire problem in a finite boundary. However, in the graphs, the $y$ values vary from 0 to 9 , and the primary velocity, secondary velocity, temperature and concentration profiles tend to zero as $y$ tends to 9. This is true for any value of $y$. Thus, we have considered finite length.

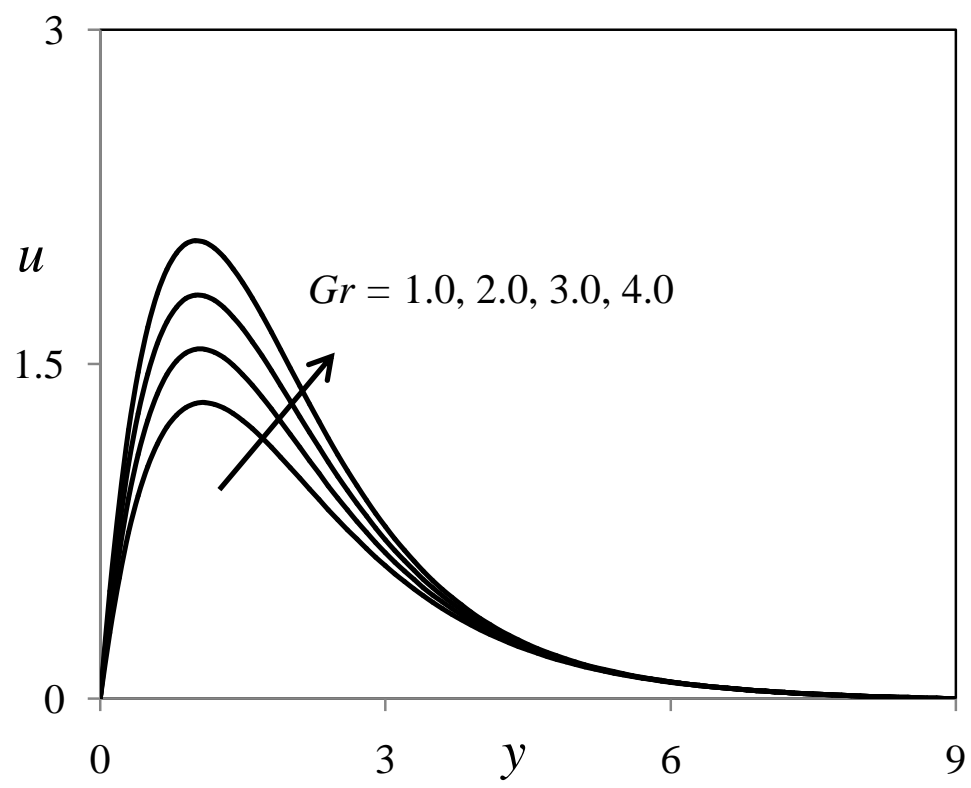

Fig. 1. Influence of Gr on primary velocity profiles 
Role of Magnetic Field on Natural Convective Towards a Semi-Infinite Vertically Inclined Plate in Presence of Hall Current with Numerical Solutions: A Finite Difference Technique

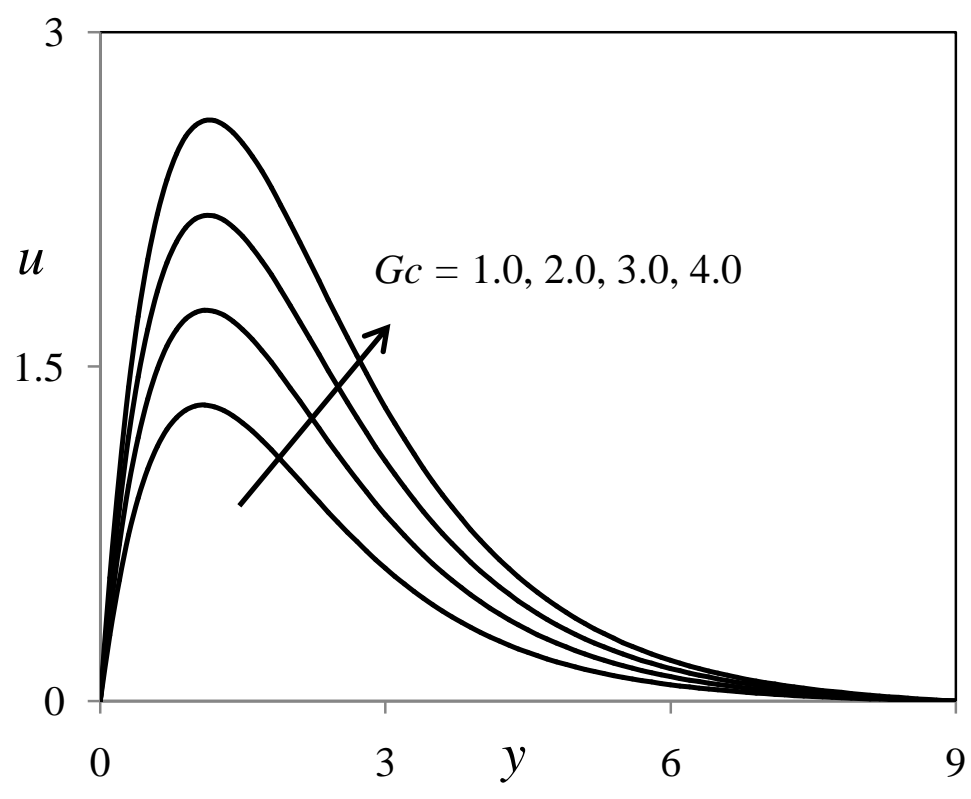

Fig. 2. Influence of Gc on primary velocity profiles

The temperature and the species concentration are coupled to the velocity via Grashof number for heat and mass transfer as seen in equation (11). For various values of Grashof number for heat and mass transfer, the primary velocity profiles $u$ are plotted in figures (1) and (2). The Grashof number for heat transfer signifies the relative effect of the thermal buoyancy force to the viscous hydrodynamic force in the boundary layer. As expected, it is observed that there is a rise in the primary velocity due to the enhancement of thermal buoyancy force. Also, as $G r$ increases, the peak values of the primary velocity increases rapidly near the porous plate and then decays smoothly to the free stream velocity. The Grashof number for mass transfer defines the ratio of the species buoyancy force to the viscous hydrodynamic force. As expected, the fluid velocity increases and the peak value is more distinctive due to increase in the species buoyancy force. The primary velocity distribution attains a distinctive maximum value in the vicinity of the plate and then decreases properly to approach the free stream value. It is noticed that the velocity increases with increasing values of Modified Grashof number. The nature of primary velocity profiles in presence of foreign species such as Hydrogen $(S c=0.22)$, Helium $(S c=0.30)$, Oxygen $(S c=0.60)$ and Ammonia $(S c=0.78)$ are shown in figure (3). The flow field suffers a decrease in primary velocity at all points in presence of heavier diffusing species.

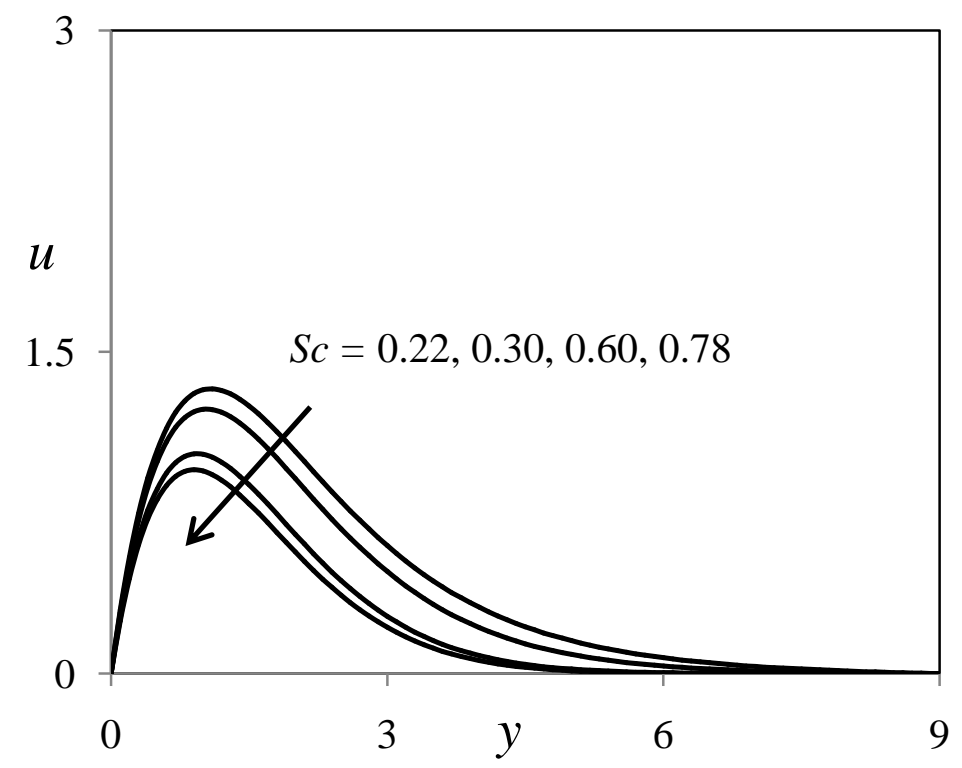

Fig. 3. Influence of Sc on primary velocity profiles 
Role of Magnetic Field on Natural Convective Towards a Semi-Infinite Vertically Inclined Plate in Presence of Hall Current with Numerical Solutions: A Finite Difference Technique

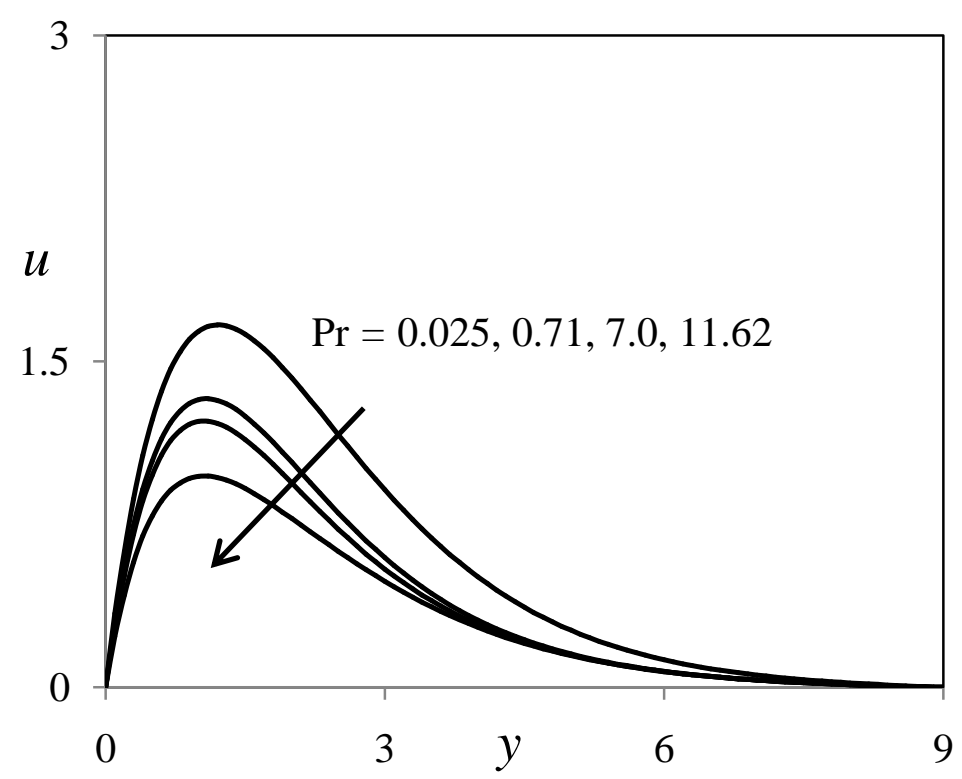

Fig. 4. Influence of Pr on primary velocity profiles

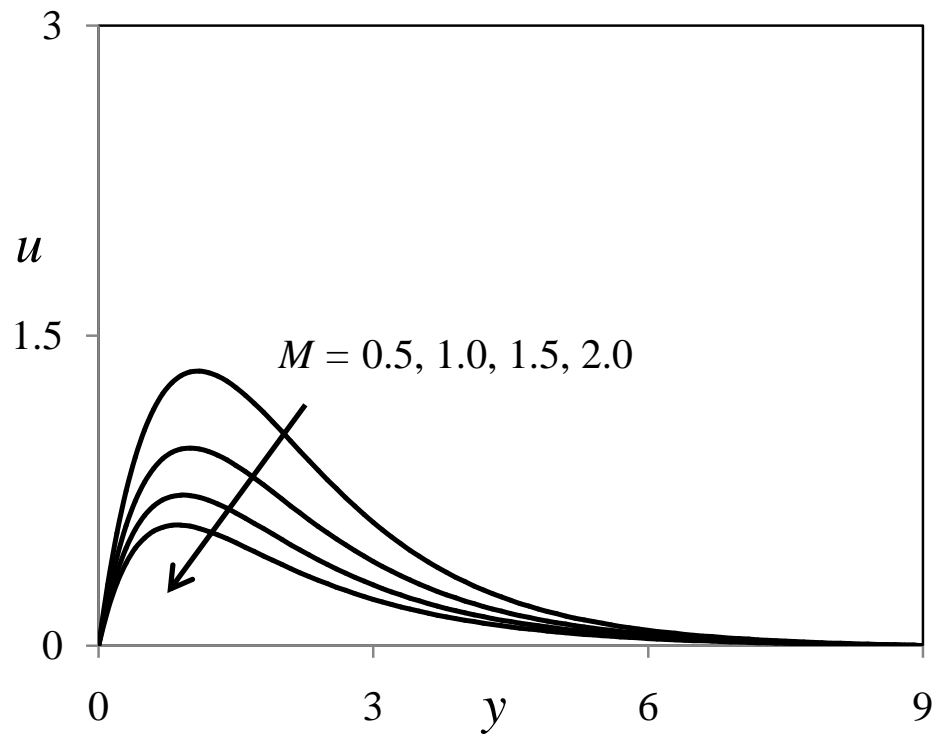

Fig. 5. Influence of $M$ on primary velocity profiles

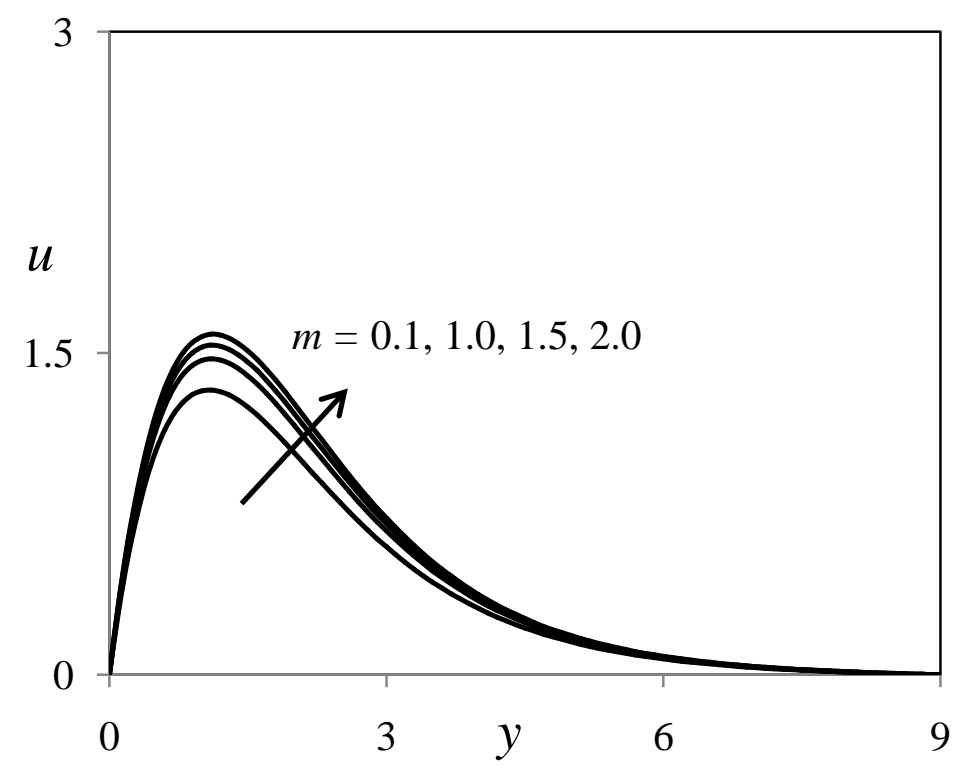

Fig. 6. Influence of $m$ on primary velocity profiles 
Role of Magnetic Field on Natural Convective Towards a Semi-Infinite Vertically Inclined Plate in Presence of Hall Current with Numerical Solutions: A Finite Difference Technique

The influence of the viscous dissipation parameter i.e., the Eckert number on the velocity and temperature are shown in figures (7) and (8) respectively. The Eckert number expresses the relationship between the kinetic energy in the flow and the enthalpy. It embodies the conversion of kinetic energy into internal energy by work done against the viscous fluid stresses. Greater viscous dissipative heat causes a rise in the temperature as well as the velocity. This behavior is evident from figures (7) and (8). In figures (9) and (10), we see the influence of the both heat and mass transfer on secondary velocity of the flow. It can be seen that as both the heat and mass transfer increases, this velocity component increases as well. In figures (9) and (10), the effects of the heat and mass transfer on the velocity are displayed. It is apparent from the figures that, the increasing values of heat and mass transfer enhance the secondary velocity. The effect of Eckert number on the secondary velocity flow field is presented in the figure (11). Here, the secondary velocity profiles are drawn against $y$ for three different values of $E c$. The Eckert number is found to accelerate the secondary velocity of the flow field at all points. In figure (12) we have the influence of the Hartmann number on the secondary velocity. It can be seen that as the values of this parameter increases, the secondary velocity increases. The nature of secondary velocity profiles in presence of foreign species such as Hydrogen $(S c=0.22)$, Helium $(S c=0.30)$, Water-vapour $(S c=0.60)$ and Ammonia $(S c=0.78)$ are shown in figure (13). The flow field suffers a decrease in secondary velocity at all points in presence of heavier diffusing species. Figure (4) depicts the effect of Prandtl number on primary velocity profiles in presence of foreign species such as Mercury $(\operatorname{Pr}=0.025)$, Air at $25^{\circ} C$ and one atmospheric pressure $(\operatorname{Pr}=0.71)$, Water $(\operatorname{Pr}=7.00)$ and Methanol $(\operatorname{Pr}=11.62)$ are shown in figure $(4)$. We observe that from figure (4), the primary velocity decreases with increasing of Prandtl number. The effect of the Hartmann number is shown in figure (5). It is observed that, the primary velocity of the fluid decreases with the increasing of the magnetic field number values. The decrease in the primary velocity as the Hartmann number increases is because the presence of a magnetic field in an electrically conducting fluid introduces a force called the Lorentz force, which acts against the flow, if the magnetic field is applied in the normal direction, as in the present study. This resistive force slows down the fluid velocity component as shown in figure (5). Figure (6) depicts the primary velocity profiles as the Hall parameter $m$ increases. We see that $u$ increases as $m$ increases. It can also be observed that $u$ profiles approach their classical values when Hall parameter $m$ becomes large

$(m>1)$.

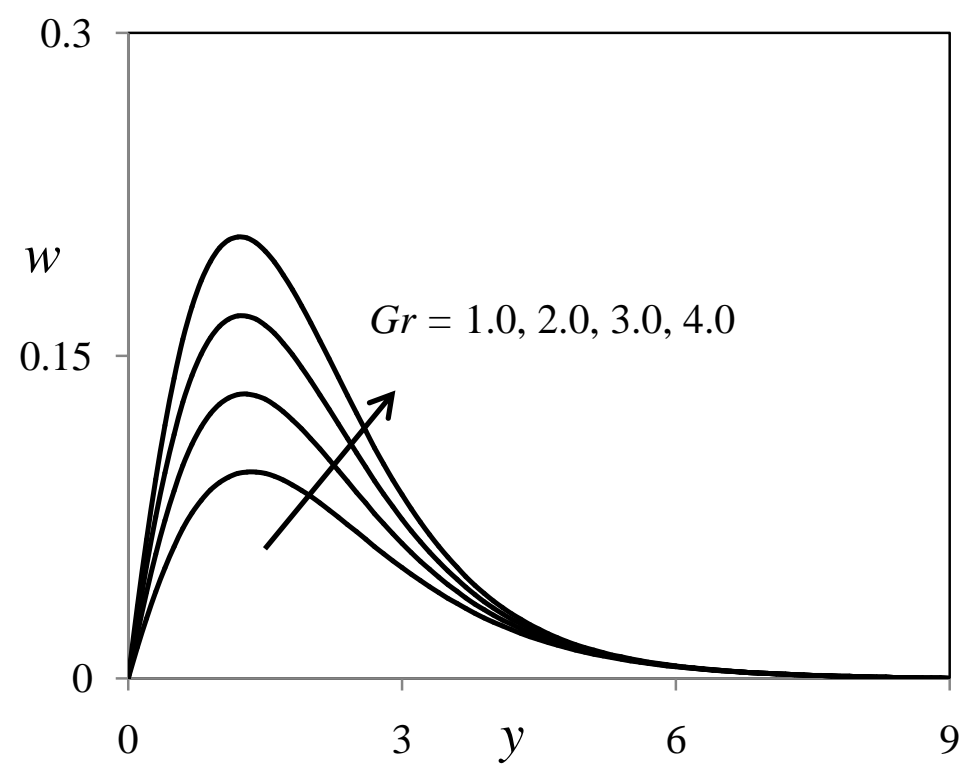

Fig. 7. Influence of Gr on secondary velocity profiles 
Role of Magnetic Field on Natural Convective Towards a Semi-Infinite Vertically Inclined Plate in Presence of Hall Current with Numerical Solutions: A Finite Difference Technique

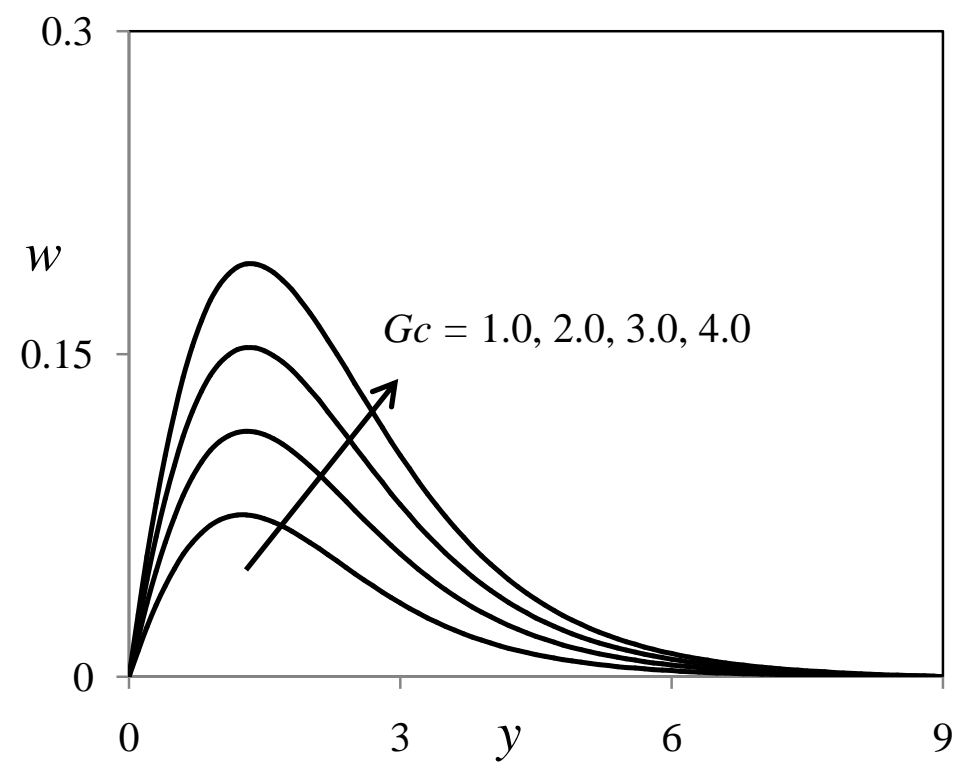

Fig. 8. Influence of Gc on secondary velocity profiles

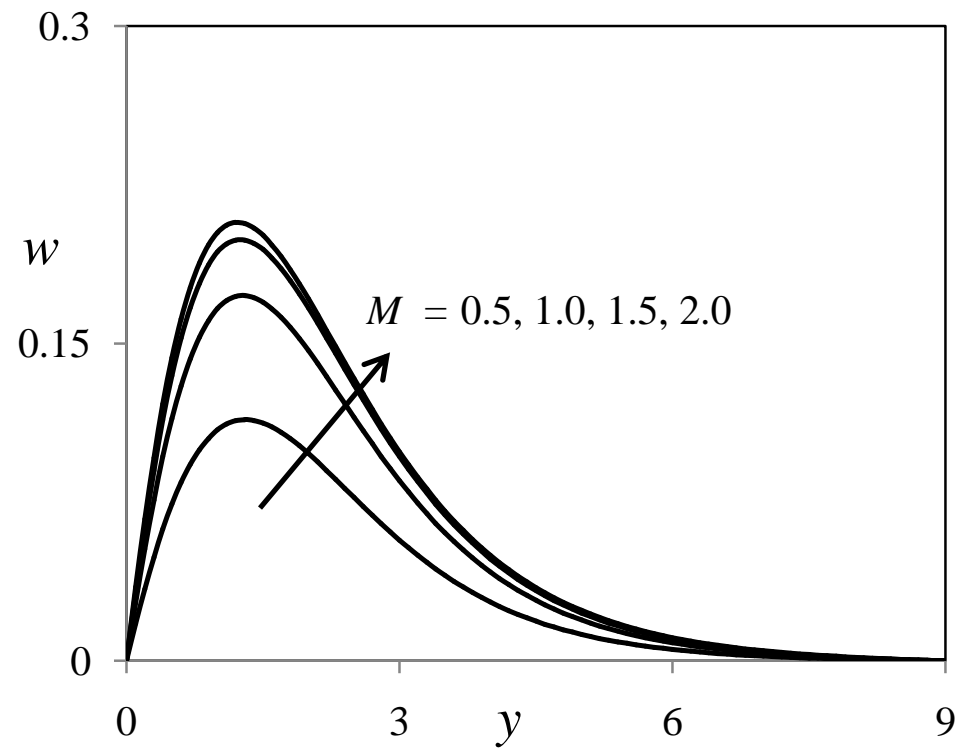

Fig. 9. Influence of $M$ on secondary velocity profiles

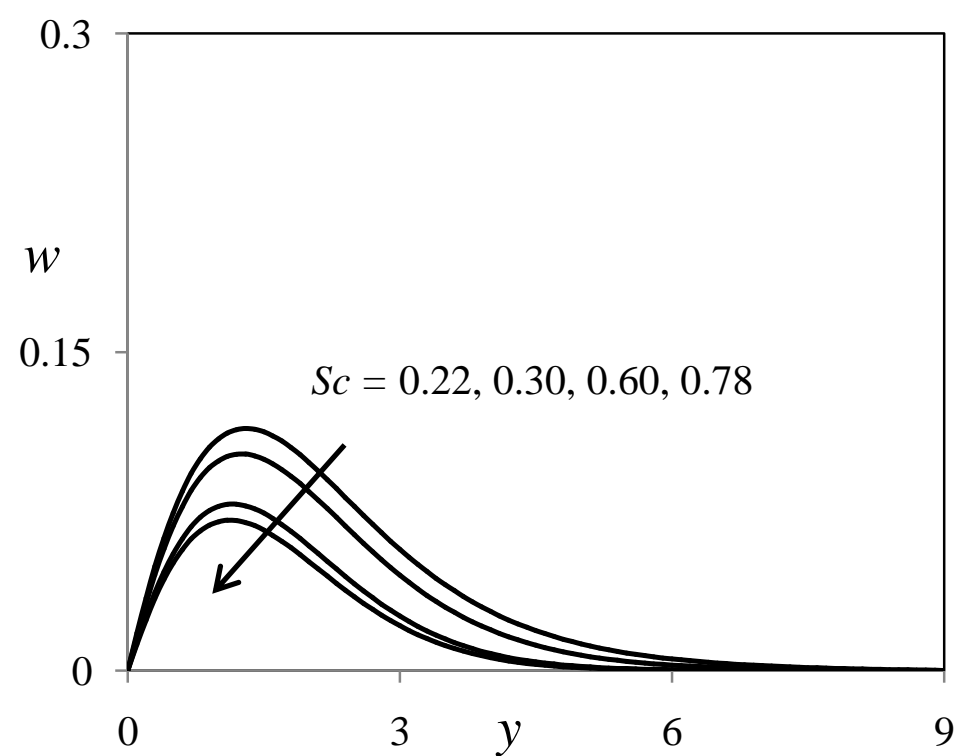

Fig. 10. Influence of Sc on secondary velocity profiles 
Role of Magnetic Field on Natural Convective Towards a Semi-Infinite Vertically Inclined Plate in Presence of Hall Current with Numerical Solutions: A Finite Difference Technique

In figures (7) and (8), we see the influence of the both heat and mass transfer on secondary velocity of the flow. It can be seen that as both the heat and mass transfer increases, this velocity component increases as well. In figures (7) and (8), the effects of the heat and mass transfer on the velocity are displayed. It is apparent from the figures that, the increasing values of heat and mass transfer enhance the secondary velocity. In figure (9), the influence of the Hartmann number on the secondary velocity. It can be seen that as the values of this parameter increases, the secondary velocity increases. The nature of secondary velocity profiles in presence of foreign species such as Hydrogen $(S c=0.22)$, Helium $(S c=0.30)$, Water-vapour $(S c=0.60)$ and Ammonia $(S c=0.78)$ are shown in figure $(10)$. The flow field suffers a decrease in secondary velocity at all points in presence of heavier diffusing species. Figure (11) depicts the effect of Prandtl number on secondary velocity profiles in presence of foreign species such as Mercury $(\operatorname{Pr}=0.025)$, Air at $25^{\circ} \mathrm{C}$ and one atmospheric pressure $(\operatorname{Pr}=0.71)$, Water $(\operatorname{Pr}=7.00)$ and Methanol $(\operatorname{Pr}=11.62)$ are shown in figure (11). It is observed that, the velocity is decreasing with increasing of Prandtl number. In figure (12) we depict the effect of Prandtl number on the temperature field. It is observed that an increase in the Prandtl number leads to decrease in the temperature field. Also, temperature field falls more rapidly for water in comparison to air and the temperature curve is exactly linear for mercury, which is more sensible towards change in temperature. From this observation it is concluded that mercury is most effective for maintaining temperature differences and can be used efficiently in the laboratory. Air can replace mercury, the effectiveness of maintaining temperature changes are much less than mercury. However, air can be better and cheap replacement for industrial purpose. This is because, either increase of kinematic viscosity or decrease of thermal conductivity leads to increase in the value of Prandtl number. Hence temperature decreases with increasing of Prandtl number. The effects of Schmidt number on the concentration field is presented in figure (13). Figure (13) shows the concentration field due to variation in Schmidt number for the gasses Hydrogen, Helium, Water-vapour, Oxygen and Ammonia. It is observed that, the concentration field is steadily for Hydrogen and falls rapidly for Oxygen and Ammonia in comparison to Water-vapour. Thus Hydrogen can be used for maintaining effective concentration field and Water-vapour can be used for maintaining normal concentration field.

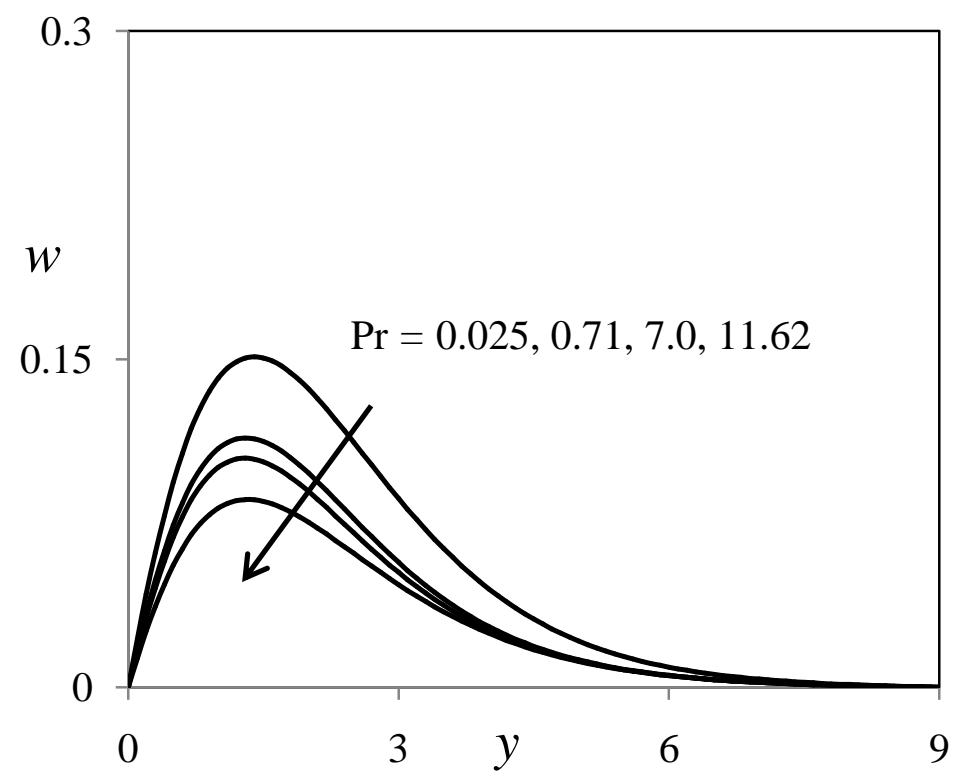

Fig. 11. Influence of Pr on secondary velocity profiles 
Role of Magnetic Field on Natural Convective Towards a Semi-Infinite Vertically Inclined Plate in Presence of Hall Current with Numerical Solutions: A Finite Difference Technique

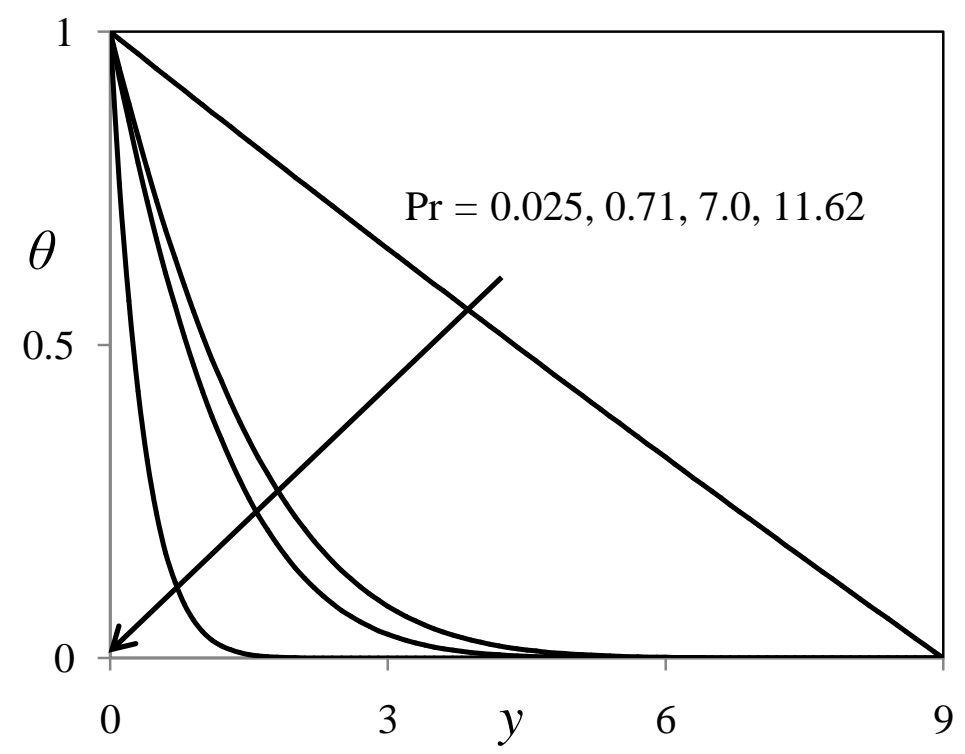

Fig. 12. Influence of Pr on temperature profiles

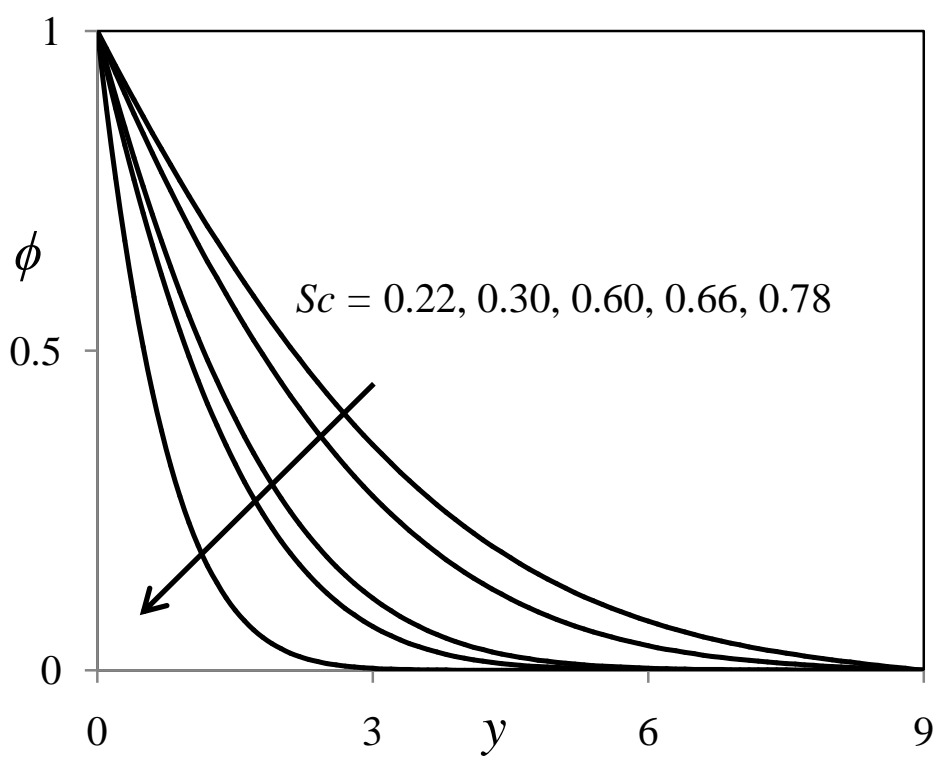

Fig. 13. Influence of Sc on concentration profiles

\section{Conclusions}

The effect of hall current on unsteady MHD flow of an electrically conducting incompressible fluid along a porous flat plate with heat and mass transfer is studied. The dimensionless equations are solved by using finite difference method. The simultaneous effects of primary velocity, secondary velocity, temperature and concentration for different parameters like Grashof number for heat transfer, Grashof number for mass transfer, Prandtl number, Schmidt number, Hartmann number and Hall parameter studied. The study concludes the following results.

1. It is observed that both the primary and secondary velocities of the fluid increases with the increasing of parameters Grashof number for heat transfer, Grashof number for mass transfer, Hall parameter and decreases with the increasing of parameters Prandtl number, Schmidt number, Hartmann number.

2. The fluid temperature increases with the decreasing of Prandtl number.

3. The Concentration of the fluid decreases with the increasing of Schmidt number. 
Role of Magnetic Field on Natural Convective Towards a Semi-Infinite Vertically Inclined Plate in Presence of Hall Current with Numerical Solutions: A Finite Difference Technique

\section{REFERENCES}

[1] Y. Dharmendar Reddy, R. Srinivasa Raju, V. Srinivasa Rao, L. Anand Babu, Hall Current effect on an unsteady MHD free convection flow past a vertical porous plate with heat and mass transfer, International Journal of Scientific and Innovative Mathematical Research, Vol. 3, Special Issue 3, pp. 884-890, 2015.

[2] Y. Dharmendar Reddy, R. Srinivasa Raju, S. Hari Prasad, L. Anand Babu, Chemical Reaction effect on an unsteady MHD free convective flow past a vertical porous plate with Hall Current, Proceedings of International Conference on Mathematical Computer Engineering-(ICMCE-2013), pp. 1206-1219 with ISBN 978-93-82338-91-8 () 2013 Bonfring.

[3] V. Srinivasa Rao, L. Anand Babu and R. Srinivasa Raju, Finite Element Analysis of Radiation and mass transfer flow past semi-infinite moving vertical plate with viscous dissipation, Journal of Applied Fluid Mechanics, Vol. 6, No. 3, pp. 321-329, 2013.

[4] Siva Reddy Sheri, R. Srinivasa Raju and S. Anjan Kumar, Transient approach to heat absorption and radiative heat transfer past an impulsively moving plate with ramped temperature, Procedia Engineering Journal , Vol. 127, pp. 893-900, 2015, DOI: 10.1016/j.proeng.2015.11.427.

[5] Siva Reddy Sheri, R. Srinivasa Raju and S. Anjan Kumar, Transient MHD free convection flow past a porous vertical plate in presence of viscous dissipation, International Journal of Advances in Applied Mathematics and Mechanics, Vol. 2, No. 4, pp. 25-34, 2015.

[6] Siva Reddy Sheri and R. Srinivasa Raju, Transient MHD free convective flow past an infinite vertical plate embedded in a porous medium with viscous dissipation, Meccanica, Vol. 51, Issue 5, pp. 1057-1068, 2016.

[7] Siva Reddy Sheri and R. Srinivasa Raju, Soret effect on unsteady MHD free convective flow past a semiinfinite vertical plate in the presence viscous dissipation, International Journal for Computational Methods in Engineering Science and Mechanics, Vol. 16, Issue 2, pp. 132-141, 2015.

[8] S. Venkataramana, K. Anitha and R. Srinivasa Raju, Thermal radiation and rotation effect on an unsteady MHD mixed convection flow through a porous medium with Hall current and Heat absorption, International Journal of Mathematical Sciences, Technology and Humanities, Vol. 2, Issue 4, pp. 593-615, 2012.

[9] S. V. Sailaja, B. Shanker, and R. Srinivasa Raju, Finite Element Analysis of MHD Casson Fluid Flow Past A Vertical Plate with the impact of Angle of Inclination, Journal of Nano fluids, Vol. 7, No. 2, pp. 383395, 2018.

[10] S. V. Sailaja, B. Shanker, and R. Srinivasa Raju, Finite Element Solutions Of Non-Newtonian Dissipative Casson Fluid Flow Past A Vertically Inclined Surface Surrounded By Porous Medium Including Constant Heat Flux, Thermal Diffusion and Diffusion Thermo, Journal of Advanced Mathematics And Applications, 2017.

[11] S. V. Sailaja, B. Shanker and R. Srinivasa Raju, Double Diffusive Effects On MHD Mixed Convection Casson Fluid Flow Towards A Vertically Inclined Plate Filled In Porous Medium In Presence Of Biot Number: A Finite Element Technique, Journal of Nano fluids, Vol. 6, pp. 420-435, 2017, https://doi.org/10.1166/jon.2017.1337.

[12] S. V. Sailaja, B. Shanker and R. Srinivasa Raju, Behaviour Of Non-Newtonian Casson Fluid On MHD Free Convective Flow Past A Vertically Inclined Surface Surrounded By Porous Medium Including Thermal Diffusion: A Finite Element Technique, Journal of Nano fluids, Vol. 6, pp. 946-955, 2017.

[13] S. Sivaiah, G. Murali, M. C. K. Reddy and R. Srinivasa Raju, Unsteady MHD Mixed Convection Flow past a Vertical Porous Plate in Presence of Radiation, International Journal of Basic and Applied Sciences, Vol. 1, No. 4, pp. 651-666, 2012.

[14] S. Sivaiah and R. Srinivasa Raju, Finite Element Solution of Heat and Mass transfer flow with Hall Current, heat source and viscous dissipation, Applied Mathematics and Mechanics (English edition), Vol. 34, No. 5, pp. 559-570, 2013.

[15] Ramya Dodda, R. Srinivasa Raju, J. Anand Rao and M. M. Rashidi, Boundary layer Viscous Flow of Nanofluids and Heat Transfer Over a Nonlinearly Isothermal Stretching Sheet in the Presence of Heat Generation/Absorption and Slip Boundary Conditions, International Journal of Nanoscience and Nanotechnology, Vol. 12, No. 4, pp. 251-268, 2016.

[16] Ramya Dodda, R. Srinivasa Raju and J. Anand Rao, Numerical Simulation Of MHD Boundary Layer Partial Slip Flow Of Nanofluids Over A Nonlinear Stretching Sheet With Suction/Injection, Journal of Nano fluids, Vol. 6, pp. 541-549, 2017, https://doi.org/10.1166/jon.2017.1334.

[17] Ramya Dodda, R. Srinivasa Raju and J. Anand Rao, Influence Of Chemical Reaction On MHD boundary Layer flow Of Nano Fluids Over A Nonlinear Stretching Sheet With Thermal Radiation, Journal of Nano fluids, Vol. 5, No. 6, pp. 880-888, 2016, DOI: http://dx.doi.org/10.1166/jon.2016.1276.

International Journal of Scientific and Innovative Mathematical Research (IJSIMR) 
Role of Magnetic Field on Natural Convective Towards a Semi-Infinite Vertically Inclined Plate in Presence of Hall Current with Numerical Solutions: A Finite Difference Technique

[18] Ramya Dodda, A. J. Chamkha, R. Srinivasa Raju, and J. Anand Rao, Effect of velocity and thermal wall slips on MHD boundary layer viscous flow and heat transfer of a nanofluid over a nonlinearly-stretching sheet: A Numerical study, Propulsion and Power Research Journal, 2017.

[19] R. Srinivasa Raju, Unsteady MHD boundary layer flow of Casson fluid over an inclined surface embedded in a porous medium with thermal radiation and chemical reaction, Journal of Nano fluids, 2018.

[20] R. Srinivasa Raju, Transfer Effects On An Unsteady MHD Free Convective Flow Past A Vertical Plate With Chemical Reaction, Engineering Transactions Journal, Vol. 65, No. 2, pp. 221-249, 2017.

[21] R. Srinivasa Raju, S. Sivaiah and J. Anand Rao, Radiation effects on unsteady MHD free convection with Hall current near on an infinite vertical porous plate, Journal of Energy, Heat and Mass Transfer, Vol. 34, pp. 163-174, 2012.

[22] R. Srinivasa Raju, S. Sivaiah and J. Anand Rao, Finite Element Solution of Heat and Mass transfer in past an impulsively started infinite vertical plate with Hall Effect, Journal of Energy, Heat and Mass Transfer, Vol. 34, pp. 121-142, 2012.

[23] R. Srinivasa Raju, Numerical Treatment Of Casson Fluid Free Convection Flow Past An Infinite Vertical Plate Filled In Magnetic Field In Presence Of Angle Of Inclination And Thermal Radiation: A Finite Element Technique, International Journal of Engineering and Applied Sciences, Vol. 8, No. 4, pp. 119133, 2016.

[24] R. Srinivasa Raju, N. Venkatesh, M. Anil Kumar and G. Jithender Reddy, Influence Of Transpiration On Unsteady Heat Transfer MHD Fluid Flow Over An Infinite Vertical Plate In Presence Of Hall Current, ARPN Journal of Engineering and Applied Sciences, Vol. 11, No. 23, pp. 14008-14013, 2016.

[25] R. Srinivasa Raju, M. Anil Kumar and Y. Dharmendar Reddy, Unsteady MHD Free Convective Flow Past A Vertical Porous Plate With Variable Suction, ARPN Journal of Engineering and Applied Sciences, Vol. 11, No. 23, pp. 13608-13616, 2016.

[26] R. Srinivasa Raju, M. Anil Kumar and K. Sarada, Y. Dharmendar Reddy, Influence of thermal radiation on unsteady free convection flow of water near $4^{\circ} \mathrm{C}$ past a moving vertical plate, Global Journal of Pure and Applied Mathematics, Vol. 11, No. 2, pp. 237-240, 2015.

[27] R. Srinivasa Raju, K. Sudhakar and M. Rangamma, The effects of thermal radiation and Heat source on an unsteady MHD free convection flow past an infinite vertical plate with thermal diffusion and diffusion thermo, Journal of Institution of Engineers: Series $C$, Vol. 94, Issue 2, pp. 175-186, DOI: 10.1007/s40032-013-0063-3, 2013.

[28] R. Srinivasa Raju, G. Jitthender Reddy, J. Anand Rao and M. M. Rashidi, Thermal Diffusion and Diffusion Thermo Effects on an Unsteady Heat and Mass Transfer MHD Natural Convection Couette Flow Using FEM, Journal of Computational Design and Engineering, Vol. 3, Issue 4, pp. 349-362, 2016, DOI: 10.1016/j.jcde.2016.06.003.

[29] R. Srinivasa Raju, G. Jithender Reddy, M. Anil Kumar and N. V. Swamy Naidu, Finite element analysis of chemically reacted fluid flow over an exponentially accelerated vertical plate, Proceedings of International Conference on Computers Aided Engineering, pp. 243-249, 2015.

[30] R. Srinivasa Raju, G. Jithender Reddy, J. Anand Rao, M. M. Rashidi and Rama Subba Reddy Gorla, Analytical and Numerical Study of Unsteady MHD Free Convection Flow over an Exponentially Moving Vertical Plate With Heat Absorption, International Journal of Thermal Sciences, Vol. 107, pp. 303-315, 2016.

[31] R. Srinivasa Raju, G. Jithender Reddy, J. Anand Rao and P. Manideep, Application of FEM to free convective flow of Water near $4^{\circ} \mathrm{C}$ past a vertical moving plate embedded in porous medium in presence of magnetic field, Global Journal of Pure and Applied Mathematics, Vol. 11, No. 2, pp. 130-134, 2015.

[32] R. Srinivasa Raju, G. Jithender Reddy and Rama Subba Reddy Gorla, Jeffrey Fluid Impact on MHD Free Convective Flow past a vertically inclined plate with Transfer Effects: EFGM Solutions, International Journal of Fluid Mechanics Research, 2018.

[33] R. Srinivasa Raju, G. Jithender Reddy and M. Anil Kumar, Viscous Dissipation Impact on MHD Free Convection Radiating Fluid Flow past a Vertical Porous Plate, AIP Conference Proceedings, 2018.

[34] R. Srinivasa Raju, G. Jithender Reddy and G. Anitha, MHD Casson Viscous Dissipative Fluid Flow Past A Vertically Inclined Plate In Presence Of Heat And Mass Transfer: A Finite Element Technique, Frontiers In Heat And Mass Transfer, Vol. 8, pp. 27, 2017.

[35] R. Srinivasa Raju, G. Aruna, N. V. Swamy Naidu, S. Vijay Kumar Varma and M. M. Rashidi, Chemically reacting fluid flow induced by an exponentially accelerated infinite vertical plate in a magnetic field and variable temperature via LTT and FEM, Theoretical and Applied Mechanics, Vol. 43, Issue 1, pp. 49-83, 2016. 
Role of Magnetic Field on Natural Convective Towards a Semi-Infinite Vertically Inclined Plate in Presence of Hall Current with Numerical Solutions: A Finite Difference Technique

[36] R. Srinivasa Raju, G. Anitha, M. M. Rashidi and Rama Subba Reddy Gorla, Study Of Grid Independence And Convergence Analysis Of FEM For 2D Incompressible MHD Mixed Convection Flow In A Darcian Porous Medium, Journal of Porous Media, 2018.

[37] R. Srinivasa Raju, G. Anitha, G. Aruna and S. Vijay Kumar Varma, Viscous dissipation impact on chemically reacting flow past an infinite vertical oscillating porous plate with magnetic field, Global Journal of Pure and Applied Mathematics, Vol. 11, No. 2, pp. 146-150, 2015.

[38] R. Srinivasa Raju, G. Anitha, and G. Jithender Reddy, Heat And Mass Transfer Effects On MHD Natural Convective Flow Past A Vertical Porous Plate Through Analytical And Numerical Results, Journal of Heat And Mass Transfer Research, 2017, DOI: 10.22075/JHMTR.2018.1854.1142.

[39] R. Srinivasa Raju, G. Anitha and G. Jitthender Reddy, Influence of Transpiration and Hall effects on unsteady MHD free convection fluid flow over an infinite vertical plate, International Journal of Control Theory and Applications, Vol. 9, Issue 23, pp. 455-462, 2016.

[40] R. Srinivasa Raju, Effects Of Soret And Dufour On Natural Convective Fluid Flow Past A Vertical Plate Embedded In Porous Medium In the Presence Of Thermal Radiation Via FEM, Journal of the Korean Society for Industrial and Applied Mathematics, Vol. 20, No. 4, pp. 309-332, 2016.

[41] R. Srinivasa Raju, Dodda Ramya, M. Anil Kumar and Rama Subba Reddy Gorla, 2D Magneto hydrodynamic Chemically Reacting Flow Past Vertically Inclined Permeable Plate Filled In Porous Medium With Convergence Analysis Of FEM, Journal of Porous Media, 2018.

[42] R. Srinivasa Raju, Combined influence of thermal diffusion and diffusion thermo on unsteady hydromagnetic free convective fluid flow past an infinite vertical porous plate in presence of chemical reaction, Journal of the Institution of Engineers: Series $C$, Vol. 97, Issue 4, pp. 505-515, 2016, DOI: 10.1007/s40032 -016-0258-5.

[43] R. Srinivasa Raju, B. Mahesh Reddy, M. M. Rashidi and Rama Subba Reddy Gorla, Numerical Solutions By EFGM of MHD Convective Fluid Flow Past A Vertical Plate Filled In Porous Medium In Presence Of Cross Diffusion Effects Via Biot number And Convective Boundary Condition, International Journal of Applied Mechanics and Engineering, Vol. 22, No. 3, pp. 613-636, 2017, DOI: 10.1515/ijame-2017-0039.

[44] R. Srinivasa Raju, B. Mahesh Reddy, M. M. Rashidi and Rama Subba Reddy Gorla, Application of Finite Element Method to Unsteady MHD Free Convection Flow Past a Vertically Inclined Porous Plate Including Thermal Diffusion And Diffusion Thermo Effects, Journal of Porous Media, Vol. 19, Issue. 8, pp. 701-722, 2016.

[45] R. Srinivasa Raju, B. Mahesh Reddy and G. Jithender Reddy, Influence Of Angle Of Inclination On Unsteady MHD Casson Fluid Flow Past A Vertical Surface Filled By Porous Medium In Presence Of Constant Heat Flux, Chemical Reaction And Viscous Dissipation, Journal of Nano fluids, Vol. 6, pp. 668679, 2017.

[46] R. Srinivasa Raju, B. Mahesh Reddy and G. Jithender Reddy, Finite Element Solutions Of MHD Free Convective Casson Fluid Flow Past A Vertically Inclined Plate Submitted In Magnetic Field In Presence Of Heat And Mass Transfer, International Journal for Computational Methods in Engineering Science and Mechanics, Vol. 18, Issue 4-5, pp. 250-265, 2017, http://dx.doi.org/10.1080/15502287.2017.1339139.

[47] R. Srinivasa Raju, Application of Finite Element Method to MHD mixed convection chemically reacting flow past a vertical porous plate with Cross Diffusion and Biot number Effects, American Journal of Heat And Mass Transfer, Vol. 4, No. 3, pp. 53-74, 2017.

[48] R. Srinivasa Raju and K. Sarada, Simultaneous Effects Of Soret and Dufour on unsteady hydromagnetic free convective chemically reacting fluid flow past an infinite vertical plate filled in porous medium, Open Journal of Applied \& Theoretical Mathematics, Vol. 2, No. 4, pp. 982-1003, 2016.

[49] R. Srinivasa Raju and K. Ramesh, Study of Grid Independence of Finite Element Method on MHD Free Convective Casson Fluid Flow with Slip Effect, AIP Conference Proceedings, 2018.

[50] P. Manideep, R. Srinivasa Raju, T. Siva Nageswar Rao and G. Jithender Reddy, Unsteady MHD Free Convection Flow of Casson Fluid over an Inclined Vertical Plate Embedded in a Porous Media, AIP Conference Proceedings, 2018.

[51] P. Manideep, R. Srinivasa Raju and G. Jithender Reddy, MHD Free Convection Heat Transfer Couette Flow in Rotating System, AIP Conference Proceedings, 2018.

[52] P. Maddilety and R. Srinivasa Raju, Hall effect on an unsteady MHD free convective Couette flow between two permeable plates, Global Journal of Pure and Applied Mathematics, Vol. 11, No. 2, pp. 125129, 2015.

[53] M. V. Ramana Murthy, R. Srinivasa Raju and J. Anand Rao, Heat and Mass transfer effects on MHD natural convective flow past an infinite vertical porous plate with thermal radiation and Hall Current, Procedia Engineering Journal, Vol. 127, pp. 1330-1337, 2015, DOI: 10.1016/j.proeng.2015.11.491.

International Journal of Scientific and Innovative Mathematical Research (IJSIMR)

Page 38 
Role of Magnetic Field on Natural Convective Towards a Semi-Infinite Vertically Inclined Plate in Presence of Hall Current with Numerical Solutions: A Finite Difference Technique

[54] K. Sudhakar, R. Srinivasa Raju and M. Rangamma, Hall effect on an unsteady MHD flow past along a porous flat plate with thermal diffusion, diffusion thermo and chemical reaction, International Journal of Physical and Mathematical Sciences, Vol. 4, No. 1, pp. 370-395, 2013.

[55] K. Sudhakar, R. Srinivasa Raju and M. Rangamma, Effects of thermal diffusion and diffusion thermo on an unsteady MHD mixed convection flow past an accelerated infinite vertical plate with viscous dissipation, International Journal of Mathematical Archive, Vol. 3, No. 8, pp. 2929-2942, 2012.

[56] K. Sudhakar, R. Srinivasa Raju and M. Rangamma, Chemical reaction effect on an unsteady MHD free convection flow past an infinite vertical accelerated plate with constant heat flux, thermal diffusion and diffusion thermo, International Journal of Modern Engineering Research, Vol. 2, Issue 5, pp. 3329-3339, 2012.

[57] K. Sarada, R. Srinivasa Raju, B. Shankar, Unsteady MHD free convection flow near on an infinite vertical plate embedded in a porous medium with Chemical reaction, Hall Current and Thermal radiation, International Journal of Scientific and Innovative Mathematical Research, Vol. 3, Special Issue 3, pp. 795$801,2015$.

[58] J. Anand Rao, S. Sivaiah, Sk. Nuslin Bibi and R. Srinivasa Raju, Soret and Radiation effects on unsteady MHD free convective fluid flow embedded in a porous medium with Heat Source, Journal of Energy, Heat and Mass Transfer, Vol. 35, pp. 23-39, 2013.

[59] J. Anand Rao, S. Sivaiah and R. Srinivasa Raju, Chemical Reaction effects on an unsteady MHD free convection fluid flow past a semi-infinite vertical plate embedded in a porous medium with Heat Absorption, Journal of Applied Fluid Mechanics, Vol. 5, No. 3, pp. 63-70, 2012.

[60] J. Anand Rao, R. Srinivasa Raju and S. Sivaiah, Finite Element Solution of heat and mass transfer in MHD Flow of a viscous fluid past a vertical plate under oscillatory suction velocity, Journal of Applied Fluid Mechanics, Vol. 5, No. 3, pp. 1-10, 2012

[61] J. Anand Rao, R. Srinivasa Raju and S. Sivaiah, Finite Element Solution of MHD transient flow past an impulsively started infinite horizontal porous plate in a rotating fluid with Hall current, Journal of Applied Fluid Mechanics, Vol. 5, No. 3, pp. 105-112, 2012.

[62] J. Anand Rao, R. Srinivasa Raju and C. D. Buchaiah, Study of MHD over a vertical plate in presence of free convection flow and Hall Current through EFGM solutions, AIP Conference Proceedings, 2018.

[63] J. Anand Rao, R. Srinivasa Raju and C. D. Buchaiah, Jeffrey Fluid Effect on Free Convective Over a Vertically Inclined Plate With Magnetic Field: A Numerical Approach, AIP Conference Proceedings, 2018.

[64] J. Anand Rao, P. Ramesh Babu, R. Srinivasa Raju and Siva Reddy Sheri, Heat and Mass transfer effects on an unsteady MHD free convective chemical reacting fluid flow past an infinite vertical accelerated plate with constant heat flux, Journal of Energy, Heat and Mass Transfer, Vol. 36, pp. 237-257, 2014.

[65] J. Anand Rao, P. Ramesh Babu and R. Srinivasa Raju, Galerkin finite element solution of MHD free convection radiative flow past an infinite vertical porous plate with chemical reaction and hall current, International Journal of Mathematical Archive, Vol. 6, No. 9, pp. 164-177, 2015.

[66] J. Anand Rao, P. Ramesh Babu and R. Srinivasa Raju, Finite element analysis of unsteady MHD free convection flow past an infinite vertical plate with Soret, Dufour, Thermal radiation and Heat source, ARPN Journal of Engineering and Applied Sciences, Vol. 10, No. 12, pp. 5338-5351, 2015.

[67] J. Anand Rao, G. Jithender Reddy and R. Srinivasa Raju, Finite element study of an unsteady MHD free convection Couette flow with Viscous Dissipation, Global Journal of Pure and Applied Mathematics, Vol. 11, No. 2, pp. 65-69, 2015.

[68] J. Anand Rao and R. Srinivasa Raju, The effects of Hall currents, Soret and Dufour on MHD flow and heat transfer along a porous flat plate with mass transfer, Journal of Energy, Heat and Mass Transfer, Vol. 33, pp. 351-372, 2011.

[69] J. Anand Rao and R. Srinivasa Raju, Hall Effect on an unsteady MHD flow and heat transfer along a porous flat plate with mass transfer and viscous dissipation, Journal of Energy, Heat and Mass Transfer, Vol. 33, pp. 313-332, 2011.

[70] J. Anand Rao and R. Srinivasa Raju, Applied magnetic field on transient free convective flow of an incompressible viscous dissipative fluid in a vertical channel, Journal of Energy, Heat and Mass Transfer, Vol. 32, pp. 265-277, 2010.

[71] G. Jitthender Reddy, R. Srinivasa Raju, P. Manideep and J. Anand Rao, Thermal Diffusion and Diffusion Thermo Effects on Unsteady MHD Fluid Flow Past A Moving Vertical Plate Embedded in Porous Medium in the Presence of Hall Current and Rotating System, Transactions of A. Razmadze Mathematical Institute Journal , Vol. 170, pp. 243-265, 2016, DOI: http://dx.doi.org/ 10.1016/j.trmi.2016.07.001. 
Role of Magnetic Field on Natural Convective Towards a Semi-Infinite Vertically Inclined Plate in Presence of Hall Current with Numerical Solutions: A Finite Difference Technique

[72] G. Jitthender Reddy, R. Srinivasa Raju, J. Anand Rao and Rama Subba Reddy Gorla, Unsteady MHD Couette Flow of Water at $4^{\circ} \mathrm{C}$ in a Rotating System in Presence of Heat Transfer with Ramped Temperature via Finite Element Method, International Journal of Applied Mechanics and Engineering, Vol. 22, No. 1, pp. pp. 145-161, 2017.

[73] G. Jitthender Reddy, R. Srinivasa Raju and J. Anand Rao, Thermal Diffusion and Diffusion Thermo impact on Chemical reacted MHD Free Convection from an Impulsively Started Infinite Vertical Plate embedded in a Porous Medium using FEM, Journal of Porous Media, Vol. 20, Issue 12, pp. 1097-1117, 2017.

[74] G. Jitthender Reddy, R. Srinivasa Raju and J. Anand Rao, Influence Of Viscous Dissipation On Unsteady MHD Natural Convective Flow Of Casson Fluid Over An Oscillating Vertical Plate Via FEM, Ain Shams Engineering Journal, http://dx.doi.org/10.1016/j.asej.2016.10.012, 2017.

[75] G. Jithender Reddy, R. Srinivasa Raju, J. Anand Rao, Finite element analysis of Hall current and Rotation effects on free convection flow past a moving vertical porous plate with Chemical reaction and Heat absorption, Proceedings of 59th Congress of ISTAM, Vol. 59-istam-fm-fp-29, pp.1-11, 2014.

[76] G. Jithender Reddy, R. Srinivasa Raju and Siva Reddy Sheri, Finite Element Analysis of Soret and Radiation effects on an transient MHD free convection from an impulsively started infinite vertical plate with Heat absorption, International Journal of Mathematical Archive, Vol. 5, No. 4, pp. 211-220, 2014.

[77] G. Jithender Reddy, P. Veera Babu, R. Srinivasa Raju, Finite element analysis of Heat and Mass transfer in MHD radiative free convection from an impulsively started infinite vertical plate, Proceedings of 59th Congress of ISTAM, Vol. 59-istam-fm-fp-150, pp.1-8, 2014.

[78] G. Jithender Reddy, J. Anand Rao, R. Srinivasa Raju, Finite element Analysis of MHD free convective Couette flow with Thermal Radiation And Viscous Dissipation, Proceedings of International Conference on Computers Aided Engineering, pp. 250-255, 2015.

[79] G. Jithender Reddy, J. Anand Rao and R. Srinivasa Raju, Chemical reaction and radiation effects on MHD free convection from an impulsively started infinite vertical plate with viscous dissipation, International Journal of Advances in Applied Mathematics and Mechanics, Vol. 2, No. 3, pp. 164-176, 2015.

[80] G. Aruna, S. Vijay Kumar Varma and R. Srinivasa Raju, Combined influence of Soret and Dufour effects on unsteady hydromagnetic mixed convective flow in an accelerated vertical wavy plate through a porous medium, International Journal of Advances in Applied Mathematics and Mechanics, Vol. 3, No. 1, pp. 122-134, 2015.

[81] D. V. V. Krishna Prasad, G. S. Krishna Chaitanya and R. Srinivasa Raju, Role Of Casson Fluid On MHD Natural Convective Flow Towards Vertically Inclined Plate With Hall Current, AIP Conference Proceedings, 2018.

[82] D. V. V. Krishna Prasad, G. S. Krishna Chaitanya and R. Srinivasa Raju, Thermal Diffusion Effect on MHD Mixed Convective Flow Along a Vertically Inclined Plate: A Casson Fluid Flow, AIP Conference Proceedings, 2018.

[83] D. V. V. Krishna Prasad, G. S. Krishna Chaitanya and R. Srinivasa Raju, Thermal Radiation Influence on MHD Flow of a Rotating Fluid with Heat Transfer Through EFGM Solutions, AIP Conference Proceedings, 2018.

Citation: B. Saidulu, " Role of Magnetic Field on Natural Convective Towards a Semi-Infinite Vertically Inclined Plate in Presence of Hall Current with Numerical Solutions: A Finite Difference Technique ", International Journal of Scientific and Innovative Mathematical Research, vol. 6, no. 2, p. 25-40, 2018. http://dx.doi.org/10.20431/2347-3142.0602003

Copyright: (C) 2018 Authors. This is an open-access article distributed under the terms of the Creative Commons Attribution License, which permits unrestricted use, distribution, and reproduction in any medium, provided the original author and source are credited. 